\title{
O USO DO TELEJORNAL PARA O ENSINO DA IMPORTÂNCIA E QUALIDADE DA ÁGUA.
}

\author{
Karen Cristina Braga Lima ${ }^{1}$
}

Fernanda Ventorim Pacheco ${ }^{2}$

\section{Antonio Fernandes Nascimento Junior ${ }^{3}$}

\section{RESUMO}

A água é um conteúdo relevante no ensino de Ciências e deve ser tratado com uma visão social, econômica, cultural e política, o que pode ser feito ao trabalhar o conteúdo na perspectiva da Educação Ambiental Crítica. Além disso, o despertar o interesse e dinamizar as aulas referentes ao tema, que pode ser feito através do uso de metodologias de baixo custo e que promovam maior participação dos alunos e integração do conteúdo com seu cotidiano. Para isso, seria interessante desenvolver um telejornal com os alunos para tratar do tema, o que aproximaria este do seu cotidiano, além de incentiva-lo a desenvolver uma leitura crítica do assunto e das informações geradas pelos meios de comunicação, já que a televisão se encontra muito presente na vida dos alunos. Para este trabalho uma metodologia foi desenvolvida com problematizações das imagens, discussão de notícias e a produção de um telejornal pelos alunos. Essa permite ao aluno desenvolver diferentes formas de linguagens, trocar vivências, discutir sobre o assunto, estimular a participação e a leitura do aluno, informar quanto a questões relevantes, refletir sobre o tema e contextualizá-lo. Essa metodologia foi aplicada na disciplina "Metodologia do ensino de Biologia" e depois os alunos da disciplina fizeram comentários a respeito da aula. Percebe-se vantagens ao trabalhar desta maneira integrada, sendo que o professor pode considerar essa metodologia para abordar o tema em sala de aula.

PALAVRAS-CHAVE: Ensino de Ciências, telejornal, água.

1 Graduanda em Licenciatura em Ciências Biológicas, Universidade Federal de Lavras (UFLA). karenbio02@hotmail.com

2 Doutora em Fisiologia Vegetal, Departamento de Biologia/ UFLA. fventorimpacheco@yahoo.com.br 3 Professor Adjunto do Departamento de Biologia da UFLA. toni nascimento@yahoo.com.br 


\title{
USING THE NEWS BULLETIN FOR TEACHING THE IMPORTANCE OF WATER AND WATER QUALITY
}

\begin{abstract}
Water is an important issue in science teaching and this issue should be addressed in a perspective social, economic, cultural and political, what can be done to work on the content from the perspective of Critical Environmental Education. Furthermore, should spark interest and boost classes about, what can be done by using low cost and methodologies that promote greater student participation and integration of the content with your daily life. For this, is interesting to develop a newscast with students to discuss the topic, and approach it from your everyday life, encourage the student to develop a critical reading of the subject and the information generated by the media, since television is very present in the lives of students. In this context a methodology was developed with problematizations images, news discussion and the production of a newscast by students. This allows students to develop different forms of languages, exchange experiences, discuss the subject, encourage participation and reading the student, inform about relevant issues, reflect on the theme and contextualize. The methodology was applied in the discipline "Methodology of teaching Biology" and then discipline students made comments about the lesson. It was possible to observe benefits to school to work in an integrated manner, and the teacher can consider the methodology to discuss the topic in class.
\end{abstract}

KEY-WORDS: Science Teaching, newscast, water.

\section{EL USO DEL BOLETÍN DE NOTICIAS PARA LA ENSEÑANZA DE LA IMPORTANCIA Y LA CALIDAD DEL AGUA}

\section{RESUMEN}

El agua es un contenido importante en la enseñanza de la ciencia y se debe tratar con un entorno social, económico, cultural y político, que se puede hacer para trabajar en el contenido desde la perspectiva de la visión Educación Crítica Ambiental. Por otra parte, debe despertar el interés y estimular las clases, qué se puede hacer mediante el uso de metodologías de bajo costo y que promuevan una mayor participación de los estudiantes y la integración de contenidos con su vida cotidiana. Para ello, sería interesante desarrollar un noticiero con los estudiantes para abordar el tema, con lo que se acercaría a su trabajo diario, y estimular al alumno para desarrollar una lectura crítica del tema y la información generada por los medios de comunicación, ya que la televisión está muy presente en la vida de los estudiantes. Para este trabajo se desarrolló una metodología con problematizaciones imágenes, noticias discusión y la producción de un noticiero por los estudiantes. Esto permite a los estudiantes desarrollar diferentes formas de comunicación, intercambiar 
experiencias, discutir el tema, fomentar la participación y la lectura del estudiante, informan sobre temas relevantes, reflexionen sobre el tema y contextualizarlo. Esta metodología se aplicó en el curso "Metodología de la enseñanza de la Biología" y después estudiantes de la disciplina hicieron comentarios acerca de la lección. Percibe enormes ventajas a la escuela para trabajar en esto de manera integrada, y el profesor puede considerar esta metodología para abordar el tema en el aula.

PALABRAS-CLAVE Enseñanza de las Ciencias, las noticias de televisión, agua.

\section{INTRODUÇÃO}

A importância do ensino do tema água se baseia no fato de ser um recurso de grande importância para os seres vivo e muito utilizado, mas não ser devidamente preservado. Informações a respeito desse tema devem ser discutidas ao longo do desenvolvimento do indivíduo, possibilitando que este construa uma relação com o meio em que vive (LAGE et. al, 2006). Trata se de um tema sempre atual e que está presente diariamente na vida dos alunos e na mídia. Assim, a sociedade é estimulada a tomar decisões em relação a este tema, mas informações a respeito da água nem sempre são divulgadas pela mídia e pela escola.

Outros fatores que indicam a relevância do estudo deste tema podem ser citados: trabalhar com o tema água abordando conceitos científicos, seu uso no cotidiano dos alunos, como também na indústria e agricultura abordando a quantidade que é gasta (MACIEL; DOMINGUES, 2001; TORRALBO; MARCONDES, 2009). Além destes aspectos, o tema viabiliza tratar aspectos voltados para a construção de uma visão social e ambiental. Permite abordar sobre a qualidade, o tratamento e a disponibilidade da água, assim como a importância de investimentos com tratamentos que são compensados pela melhoria da saúde pública. Essa abordagem é contextualizada permitindo uma aproximação do conteúdo com o cotidiano do aluno (MACIEL; DOMINGUES, 2001; TORRALBO; MARCONDES, 2009). No entanto, este tipo de abordagem é pouco utilizada pelos professores ao ensinarem este tema em sala de aula, dificultando a compreensão e reflexão do conteúdo pelo aluno (MACIEL; DOMINGUES, 2001; TORRALBO; MARCONDES, 2009). Neste sentido, a postura 
que a escola terá diante deste tema precisa ser pensada, de modo a colaborar com a formação para a participação do cidadão nas decisões exigidas na sociedade atual (TORRALBO; MARCONDES, 2009).

Sendo assim, uma alternativa pedagógica é abordar o tema água na perspectiva da educação ambiental crítica (EAC) que permite trabalhar o problema ambiental envolvido a este recurso natural, considerando seu contexto social, político, econômico e cultural. Permite a analise das relações entre essas dimensões e sobre o atuar no ambiente em uma perspectiva global. A EAC também questiona as relações sociais de exploração e dominação, buscando uma transformação social (JACOBI, 2005; LOUREIRO et al., 2009).

Nesta perspectiva, o objetivo deste trabalho foi a construção e avaliação de uma estratégia pedagógica para o ensino do tema água de forma crítica e contextualizada, a partir da construção de um telejornal na sala de aula.

\subsection{O USO DO TELEJORNAL NO ENSINO}

A informação e a cultura geradas pelas Tecnologias da Informação e Comunicação (TIC) podem colaborar na formação cidadã e permitir que as pessoas percebam as dimensões globais da existência, conhecendo a diversidade do mundo e construindo o entendimento das desigualdades da sociedade. Esse tipo de informação deveria ser acessado por todas as pessoas, mas por questões culturais, sociais e econômicas muitas delas não possuem o acesso e são marginalizadas (ANDRADE; SILVA, 2008).

Dentre essas tecnologias, a com maior acessibilidade para os brasileiros é a televisão, que é vista como uma forma de lazer, mas ela também desempenha um papel formador do indivíduo. O conteúdo divulgado por esta mídia é selecionado e conduzido para a sociedade, no entanto, apresentando apenas fragmentos da informação real. Por isso é importante o aluno compreender a dinâmica do processo e 
estar apto pra realizar questionamentos e interpretações a respeito das informações recebidas (ANDRADE; SILVA, 2008; VAZ, 2009).

A inserção da mídia televisiva na metodologia de ensino pode aproximar tanto o professor como o conteúdo dos alunos. Sendo assim, o professor como mediador deve levar esta perspectiva da mídia para sala de aula e preparar os alunos para questionarem os fatos. Esses fatores juntamente com a facilidade de recursos tecnológicos, a necessidade da educação em utilizar diferentes tipos de recursos, a presença dos meios de comunicação na vida dos alunos, reforçam a importância da interação da comunicação e a educação (VAZ, 2009).

Poucos professores trabalham com os jornais em sala de aula, embora os alunos demonstrem interesse neste tipo de atividade. Segundo citações de alunos no trabalho de Vaz (2009), a importância de trabalhar com jornais deve se a facilitação do aprendizado; obtenção de informações; presença dos jornais no cotidiano; compartilhamento de opiniões diferentes em sala de aula e o contato dos alunos com esse meio de comunicação.

As metodologias educativas usando os meios de comunicação apresentam diferentes vantagens no processo de ensino e aprendizagem como o uso de diferentes formas de linguagem, também possibilita a construção do pensamento crítico quanto ao conteúdo trabalhado e também da informação recebida pela mídia (MARCUSCHI, 2001; ZANCHETTA-JUNIOR, 2005).

Além disso, a participação dos alunos na construção de um telejornal torna o conteúdo escolar mais atrativo e incentiva o trabalho coletivo. Também possibilita o conhecimento das habilidades individuais, permitindo seu contato com diferentes tipos de textos para posteriormente construir seu próprio roteiro de trabalho (LIMA, 1997).

Em uma pratica escolar, usando a confecção de um jornal impresso, foi verificado que as crianças trabalharam de forma mais motivada e trocaram sentimentos e impressões (PÉREZ et al., 2008). Em outra situação de uso do telejornal, relatada por SANTOS (2012), foi observado que, até mesmo os alunos 
tímidos em sala conseguiram bom desempenho diante das câmeras, enquanto outros alunos se sobressaíram na organização e capacidade de liderança de grupo.

\section{DESENVOLVIMENTO}

Este trabalho foi produzido durante a disciplina de Metodologia do Ensino de Ciências e teve sua sequência na disciplina de Metodologia do Ensino de Biologia, ambas do curso de Ciências Biológicas - Licenciatura, da Universidade Federal de Lavras (UFLA).

Os alunos da disciplina escolheram um tema do Currículo Básico Comum - CBC (MINAS GERAIS, 2005) para desenvolver uma metodologia para o ensino do conteúdo. No caso deste trabalho o tema escolhido foi água. O trabalho foi desenvolvido da seguinte maneira: primeiro foi desenvolvida a metodologia durante um ano letivo nas disciplinas de Metodologia de Ensino. Durante essas disciplinas, a metodologia foi apresentada no Museu de História Natural (MHN) da UFLA durante um Simpósio de Ensino de Ciências, no qual a estratégia foi discutida com os alunos das referidas disciplinas e os alunos da licenciatura participantes do PIBID (Programa Institucional de Bolsas de Iniciação à Docência) de Biologia da UFLA. Posteriormente, a aula foi aplicada durante a disciplina e, em seguida, avaliada pelos alunos participantes.

A aula é referente ao tema cinco do $\mathrm{CBC}$ : qualidade da água e qualidade de vida, da disciplina de Ciências. O tópico do CBC a ser tratado neste tema é: "Disponibilidade e Qualidade da Água". Esta metodologia aborda os aspectos políticos, sociais e culturais deste tema, possibilitando uma discussão dentro da Educação Ambiental.

\subsection{METODOLOGIA PROPOSTA: CONSTRUÇÃO DE UM TELEJORNAL}


A metodologia proposta para o ensino deste conteúdo foi o desenvolvimento de um telejornal pelos alunos. A atividade contou com cinco momentos em uma sequência didática de quatro aulas, os quais são caracterizados a seguir.

No primeiro momento o tema é contextualizado por meio de imagens e perguntas problematizadoras, buscando o conhecimento prévio dos alunos e a associação com as observações do dia-a-dia, assim construindo o conhecimento do aluno. As imagens abordam a problemática relacionada à importância da água para diferentes seres vivos e seu ciclo, fazendo referências aos estados físicos da água e as diferenças entre água potável e poluída, focando na importância e existência do seu tratamento. As imagens são mostradas aos alunos por meio de slides e as problematizações estabelecidas antes da aula, outras surgem com o seu desenvolvimento.

No segundo momento os alunos são divididos em dois grupos para lerem diferentes notícias. A notícia do primeiro grupo é Pavão-Pavãozinho e Cantagalo Ganham Sistema de Distribuição de Água (FREITAS, 2014); e a notícia do segundo grupo é Transposição do Rio São Francisco Ganha Impulso em ano de Eleição (BOADLE; MARCELINO, 2014). Após a leitura cada grupo apresenta as ideias principais da notícia e debatem, com a mediação do professor, os assuntos que envolvem questões de Educação Ambiental Crítica.

Após a discussão os alunos são divididos em quatro grupos temáticos por meio de sorteio e recebem um texto com informações sobre diversos conteúdos relacionados com a água (importância da água, ciclo da água, água potável, tipos de poluição da água, como é feito o tratamento da água, distribuição geográfica e política da água). Estes textos servem como base para os alunos elaborem reportagens para a execução do telejornal. Durante este processo o professor deve estar presente esclarecendo as dúvidas dos alunos, acompanhando o desenvolvimento da atividade e estimulando a participação de todos. São os seguintes grupos:

Grupo1: Importância da água para os seres vivos; 
Grupo 2: Estados físicos da água;

Grupo 3: Ciclo da água;

Grupo 4: Água potável e sua distribuição.

Após esse momento e com a leitura dos textos informativos, cada grupo constrói uma manchete relacionada ao tema sorteado. As manchetes devem ser produzidas estabelecendo uma ligação entre o conteúdo/tema e os acontecimentos do dia-a-dia dos alunos que são vistos em jornais. Depois de cada grupo organizar sua reportagem para o jornal, os grupos discutem e propõem um roteiro e um nome para o telejornal, elencando os apresentadores âncoras e a forma de apresentação. Esta forma de organização pode ser modificada dependendo da estrutura da escola, em que, por exemplo, pode-se confeccionar um jornal impresso com auxílio do professor de informática.

Neste momento, também, os alunos podem propor alguma estrutura para a gravação do telejornal, como microfones, câmera entre outros. No último momento o jornal deve ser gravado. Após a apresentação o professor terá, como base no que foi montado pelos alunos, fundamento para discutir as questões abordadas, esclarecer as dúvidas, ouvir a opinião dos alunos e levantar novas questões. Além dessas questões o professor deve aproveitar esse momento para trabalhar como os assuntos são tratados pelas mídias, os interesses envolvidos nesse processo e a importância que tem de o aluno buscar fundamento nas notícias, tendo um olhar crítico quando ler, assistir ou ouvir uma reportagem.

A avaliação deve ser feita pela participação dos alunos durante toda a atividade. O professor é mediador buscando esclarecer as dúvidas e a participação de todos, pois esta será a base para a avaliação do conhecimento construído e da eficiência da metodologia. Ao final, o telejornal poderá ser disponibilizado para toda a escola em uma televisão, por exemplo.

\subsection{O DESENVOLVIMENTO DA AULA}


Esta sequência foi desenvolvida na aula durante a disciplina de Metodologia de Ensino. O telejornal aconteceu da seguinte maneira: a encenação do jornal iniciou com os âncoras falando as manchetes das notícias que seriam apresentadas no jornal. Depois um dos âncoras anunciou a primeira reportagem e chamou ao vivo uma repórter que está em uma cidade que acabou de receber o tratamento d'água. Essa repórter entrevistou a personagem de duas moradoras dessa cidade retratando as condições dessa população antes e depois do tratamento e abordando também a questão de saúde. Após esse momento, o âncora chamou o repórter da previsão do tempo, que traz uma abordagem do ciclo da água de uma forma cômica, demonstrando sua visão sobre o clima instável na sua cidade. Para finalizar, um dos âncoras apresentou a notícia que retrata a importância da água abordando a escassez d'água.

\section{RESULTADOS E DISCUSSÔES}

Após a prática houve a avaliação dos alunos que participaram da aplicação da aula na disciplina de Metodologia de Ensino de Biologia. A mesma foi gravada e analisada. Segue a transcrição dos trechos selecionados das falas que expressaram as ideias principais sobre a aplicação da aula. O P indica o aluno participante.

\subsection{TRECHOS SELECIONADOS DA AVALIAÇÃO DOS PARTICIPANTES}

P1: "Eu gostei muito, acho que quando você traz uma notícia, motiva a discussão dos alunos. Eles ficam com vontade de falar, de discutir. E também a participação, um aluno que tem mais vergonha em fazer com que ele apresente, dá uma oportunidade de todo mundo falar." 
P2: “... todo mundo envolveu por mais que só alguns tenham apresentado, todo mundo foi envolvido no trabalho... Foi muito bom, ainda mais que pode envolver o humor que eu acho que segura um pouco à atenção das pessoas."

P3: “... Uma coisa que eu achei bacana, é que, você tá apresentando um trabalho, você tem $50,70 \%$ da turma prestando atenção em você e o resto da turma tá fazendo outra coisa, conversando, viajando, sei lá. Fazendo desse jeito todo mundo prestou atenção".

P3: “... tipo aqui na faculdade mesmo você vê uma galera que não sabe de nada que tá acontecendo desse negócio, ou só sabe daquilo que tá acontecendo que está muito a vista e fica tipo assim, ah eu trabalho com isso então vou ler só sobre isso e não quero saber do resto. $E$, acho que isso da pessoa ser assim, vai muito da formação que ela teve na base, porque se quando ela é mais nova ela é estimulada a ler sobre várias coisas, ela não vai perder isso. Então esse tipo de metodologia que vai te estimular a ler, a pesquisar, não somente na parte do jornal, mas qualquer metodologia que te estimule a fazer esse tipo de pesquisa sobre o que está acontecendo no seu entorno é muito válida".

P4: "Eu gostei muito da prática porque faz com que os alunos se interagem..."

P4: "...você trabalha a questão da notícia, hoje em dia quase ninguém lê, procura notícia mais, então você trabalha isso com os adolescentes. Você também trabalha a leitura com eles, eles podem através disso aprender a ler um jornal ou uma revista, porque assim é mais prazeroso, fixa melhor e acaba trabalhando a leitura. $E$ trazendo contextos novos, eu achei assim ótimo o que elas fizeram, gostei da ideia, e de colocar os alunos para construírem um jornal em cima disso, eu achei muito bom".

P5: "E assim essa questão de vocês trazerem notícias pra gente estimula, depois o aluno vai procurar mais noticias e esse toque que vocês deram no final de notícias verdadeiras ou não, também estimula a gente a não só assistir o jornal globo e tal, e tentar procurar mesmo, a fundo, o que é aquela noticia, não só aquilo que é passado na televisão, uma coisa rápido, porque às vezes pode não ser aquilo que tá parecendo pra gente". 
P6: "eu acho interessante trazer isso, porque hoje em dias as crianças não têm curiosidade de ler...".

P7: "as notícias que vocês trazem servem para contextualizar a situação do Brasil. E serve como maneira informativa, querer aguçar um pouco mais a ideia deles, quererem buscar informações do que está acontecendo no seu próprio país, no seu próprio estado".

P8:" Então, eu gostei muito. Achei muito bacana de deixar livre pra gente criar o jornal como a gente queria, mas com esse tema pra nortear a gente. E também a possibilidade da gente estar em contato com outras informações. Porque quando fala em seca a gente sempre pensa. Ah nordeste, né, seca. E as pessoas tem mania de tipo assim: ah não é perto de mim, então não tenho nada a ver com isso. Então a gente tem essa mania mesmo de se importar com as coisas quando somente afeta a gente de forma direta".

P9: “... porque essa questão do jornal deu também uma abrangência muito pra outras questões que envolviam água. Porque a água em si, acaba que todo mundo já sabe um pouco (....), mas foi uma notícia que deu uma discussão bem política, assim, sobre a transposição do rio São Francisco, e eu achei bem legal por dar oportunidade disso mesmo, de trazer outras discussões, não só do jornal assim, mas com um cunho mas político que quase nunca é estimulado dentro de sala em assuntos meio que assim corriqueiros."

P10: “... Eu achei muito legal, e a questão política, eu acho que é um ponto muito importante pra gente pensar como professor, sempre ne! Porque tem, como você mesmo falou, será que essa questão é verdadeira ou não é? tendenciosa? Tem muita história ai, tem muito interesse que a gente não tem a menor ideia que se passa em cada notícia que a gente lê, e em cada coisa que acontece ai. Eu acho que é importante a gente tentar construir o conhecimento, em sair do método tradicional, sei lá, de conseguir usar ferramentas e metodologias que ajudam a construir cidadãos críticos". 
P11: "Então eu achei muito bacana, achei que vocês direcionaram muito bem, as discussões foram muito bem construídas. E eu gostei muito também, até porque a notícia do grupo que eu estava participando pegou foi da transposição do Rio São Francisco e a perspectiva muito crítica da notícia que você não costuma ver nos jornais, principalmente nos jornais televisionados pelas grandes emissoras".

\subsection{A ANÁLISE DAS FALAS}

As falas expressas em P1,P2,P3a e P4b indicam que a produção de um jornal desperta a participação dos alunos na aula, assim como foi visto no trabalho de Pérez e colaboradores (2008) e que, além disso, traz a importância dessa metodologia para a troca de percepções e vivencias dos alunos. Também verificamos a participação dos alunos mais tímidos, como dito por $\mathrm{P} 1$, possibilitando o desenvolvimento de diversas características dos alunos, como organização e liderança como argumenta Santos, (2012).

Desta forma, a metodologia adotada favoreceu o intermédio do aluno no processo de aprendizagem, privilegiando situações ativo-participativas, visando à socialização do saber, à construção e reconstrução coletiva de conhecimentos, de análise, de avaliação e resolução de problemas, bem como ao desenvolvimento de habilidades, valores e atitudes. Metodologias como esta podem tornar os alunos integrantes do meio social. Adicionalmente, permitiu despertar nos alunos, o que eles precisavam saber sobre os recursos hídricos e suas questões ambientais.

As falas observadas em P3b,P4b,P5,P6,P7 e P8 indicam que os alunos não se interessam em buscar informações e que o desenvolvimento do telejornal possibilitou os alunos a buscarem sua informação, ler e estimulou a curiosidade. Assim, essa estratégia pedagógica é importante, pois estimula os alunos a pesquisarem para construir o conhecimento, além de possibilitarem que o professor leve para a sala de aula assuntos atuais, o que permitem que o aluno se informe e seja mais consciente 
sobre a sua realidade e capaz de conhecer e questioná-la (MACIEL; DOMINGUES, 2001).

É importante também, como está expresso na fala do P5, que o professor faça a mediação entre o aluno e a leitura sobre a mídia, possibilitando ao aluno desenvolver uma visão crítica e capaz de questionar e interpretar as informações recebidas. Além disso, o uso do telejornal no ensino pode abranger uma discussão a preocupação das fontes de informações buscadas pelos alunos e apresentar para eles que muitas vezes existem manipulações impostas pela mídia. Assim, esta metodologia permite a reflexão dos educadores sobre sua tarefa social diante de objetivos educacionais mais amplos, voltando para a realidade vivida pelos alunos, transformando a teoria em prática (VAZ, 2009).

As falas identificadas em P9,P10 e ,P11 ressaltaram a importância de trabalhar com uma perspectiva crítica e politica que envolvem o tema, então ressalvam a relevância em abordar o conteúdo água com questões sociais, ambientais e políticas permite a contextualização do tema, possibilitando que o aluno conheça percepções que não são tratadas diariamente (MACIEL; DOMINGUES, 2001; TORRALBO; MARCONDES, 2009), assim contribuindo para a sua formação como cidadão.

Nesta perspectiva que Marques (2013) procurou trabalhar os recursos hídricos de uma forma crítica usando os problemas de tratamento de esgoto, o que segundo o autor possibilitou a reflexão dentro da construção de conhecimento dos alunos, abordando a realidade local e os processos tecnológicos de tratamento que existem e o limitado acesso da sociedade a esse. A abordagem desse trabalho também permitiu a construção do conhecimento relacionado à desigual distribuição de água tratada, mostrando que esse problema não é tão longe da realidade dos alunos que participaram do projeto.

\section{CONCLUSÃO}


A atividade realizada, abordando o conteúdo político e crítico com o sistema econômico atual, possibilitou uma discussão, não somente de cunho científico, mas também crítico da realidade. Essa discussão possibilitou um entendimento mais global do assunto. Ressaltou-se a importância do aluno se enxergar como parte do ambiente, permitindo uma aproximação do conteúdo com o seu cotidiano.

Além da importância do conteúdo trabalhado por esta metodologia, observouse a importância de abordar os aspectos da mídia, neste caso o telejornal, para incentivar discussões e reflexões sobre os meios de comunicação.

Assim, a prática envolvendo a produção de um telejornal mostrou-se capaz de contribuir na construção do conhecimento dos alunos de forma contextualizadora e, ao mesmo tempo, motivacional, trazendo-os, além do conteúdo ensinado, para uma visão crítica do papel da água na sociedade contemporânea.

\section{REFERÊNCIAS}

ANDRADE, L. M.; SILVA, F. C. Tecnologias de informação e comunicação: as influências das novas tecnologias perante a sociedade. In: 4 Seminário Nacional "O Professor e a Leitura do Jornal", 2008, Campinas/SP. Anais do $4^{\circ}$ Seminário Nacional "O Professor e a Leitura do Jornal", 2008. v. único.

BOADLE, A.; MARCELINO, U. Transposição do rio São Francisco ganha impulso em ano de eleição. Disponível em: <http://noticias.uol.com.br/ultimas-noticias/reuters/2014/02/10/especial-transposicao-dorio-sao-francisco-ganha-impulso-em-ano-de-eleicao.htm>. Acesso em 01/09/2014.

FREITAS, C. Pavão-Pavãozinho e Cantagalo ganham sistema de distribuição de água. Jornal do Brasil. Disponível em: <http://m.jb.com.br/rio/noticias/2014/02/04/pavao-pavaozinho-e-cantagaloganham-sistema-de-distribuicao-de-agua/>. Acesso em 01/09/2014.

JACOBI, P. R. Educação Ambiental: o desafio da construção de um pensamento crítico, complexo e reflexivo. Educação e Pesquisa (USP), São Paulo, v. 31, n. 2, p. 234-250, maio/ago. 2005.

LAGE, F.; NOGUEIRA, M. G.; FORESTI, M. C. P.. A importância do tema água doce no ensino fundamental: uma proposta de aulas teórico-práticas. PINHO, S. Z. de; SAGLIETTI, J. R. C. (Org.). Núcleos de Ensino. São Paulo: Editora Unesp 2006, v. 1, p. 49-68. 2006. Disponível em:<http://www.unesp.br/prograd/PDFNE2004/artigos/eixo2/aimportanciadotemaguadoce.pdf >. Acesso em 20. Junho.2014.

LIMA, S. F. Alunos da sexta série produzem uma revista. Comunicação \& Educação São Paulo: Moderna, n.10, p.98-103, 1997. 
LOUREIRO, C. F. B.; TREIN, E.; TOZONI-REIS, M. F. DE C.; NOVICKI, V. Contribuições da teoria marxista para a educação ambiental crítica. Cadernos Cedes, Campinas, vol. 29, n. 77, p. 81-98, jan./abr. 2009. Disponível em: <http://www.cedes.unicamp.br>. Acesso em 01/09/2014

MACIEL, L. S. B.; DOMINGUES, A. L.. A água e seus múltiplos enfoques no ensino de ciências no nível fundamental. Acta Scientiarum (UEM), Maringá, v. 8, n. 3, p. 383-343, 2005.

MARCUSCHI, L. A.. Da Fala para a Escrita: Atividades de Retextualização. ${ }^{1}{ }^{a}$. ed. São Paulo: Editora Cortez, 133p .2001.

MARQUES, L. R. Tratamento de Esgoto: um Texto Didático para o Ensino Médio. Trabalho de Conclusão de Curso de Licenciatura em Química. Universidade De Brasília, Instituto De Química. Brasília. 2013.

MINAS GERAIS. Secretaria de Estado de Educação de Minas Gerais. Conteúdo Básico Comum: Ciências da Natureza Educação Básica - Ensino Fundamental (5a a 8a séries). 2005.

PÉREZ, B. C.; PÓVOA, J.; MONTEIRO, R.; CASTRO, L. R.. Cidadania e Participação Social: um estudo com crianças no Rio de Janeiro. Psicologia \& Sociedade, v.20, n.2, p.181-191, 2008.

SANTOS, M. C. V.. Projeto Telejornal: Um relato de experiência. IX Encontro Virtual de Documentação em Software Livre e VI Congresso Internacional de Linguagem e Tecnologia. Anais Online, n.1, v.1, 2012. Disponivel em: < http://www.periodicos.letras.ufmg.br/index.php/anais_linguagem_tecnologia/article/view/1911>. Acesso em 20. Junho.2014.

TORRALBO, D., MARCONDES, M. E. R.. A "água" como tema ambiental no ensino de química: o que pensam os pesquisadores. Revista eletrônica do Mestrado em Educação Ambiental, v. 22, p.1-12. 2009. Disponivel em: <http://www.seer.furg.br/remea/article/view/2810/1589>. Acesso em 20. Junho.2014.

VAZ, T. C. V.. O uso do telejornal na educação escolar. Instituto Metodista de Educação Superior, 2009.

http://www2.metodista.br/unesco/1_Regiocom\%202009/arquivos/trabalhos/REGIOCOM\%206\%20-

\%200\%20uso\%20do\%20telejornal\%20na\%20educa\%C3\%A7\%C3\%A30\%20escolar\%20-

\%20Tyciane\%20Vaz.pdf> . Acesso em 20. Junho de 2014.

ZANCHETTA-JUNIOR, J. Desafios para a abordagem da imprensa na escola. Educação e Sociedade, Campinas, v.26, n.93, p.1497-1510, 2005. 